\title{
Effect of Behaviour Change Communication on Iodised Salt Utilization and Median Urine Iodine Concentration among Children Growth Age 6 -59 Months in Central Highland of Ethiopia: Cluster Randomized Control Trial
}

\author{
Abebe Ferede $^{1 *}$, Tefera Belachew ${ }^{2}$ and Muluemebet Abera ${ }^{3}$ \\ ${ }^{1}$ Department of Public Health, College of Health Science, Arsi University, Ethiopia \\ ${ }^{2}$ Nutrition and dietetics Department, Jimma University, Ethiopia
}

${ }^{3}$ Department of Population and Family Health, Jimma University, Ethiopia

*Corresponding author: Abebe Ferede, Department of Public Health, Arsi University, Asella, Oromia state, Ethiopia.

\section{ARTICLE INFO}

Received: 业 March 04, 2020

Published: 幽 March 12, 2020

Citation: Abebe F, Tefera Belachew, Muluemebet A. Effect of Behaviour Change Communication on Iodised Salt Utilization and Median Urine Iodine Concentration among Children Growth Age 6 -59 Months in Central Highland of Ethiopia: Cluster Randomized Control Trial. Biomed J Sci \& Tech Res 26(4)-2020. BJSTR. MS.ID.004372.

Abbreviations: $\mathrm{CI}$ : Confidence Interval; Diff: Difference; Ht: Height; HFA: Height for Age; IDD: Iodine Deficiency Disorder; L: Litter: $\mu \mathrm{g} / \mathrm{L}$ : Microgram per litter of urine; MD: Mean Difference; Z: Z score; SD: Standard Deviation; SE: Standard Error; P: significance UIC: Urine Iodine Concentration; MUIC: Median Urine Iodine Concentration
ABSTRACT

The most daunting challenge to control Iodine Deficiency Disorder (IDD) in Ethiopia is accessing iodised salt with adequate quantity of iodine. Fundamentally, measuring Median Urine Iodine Concentration (MUIC) is good surrogate marker of the amount of iodine found in plasma thyroxine. There was no study in Ethiopia that evaluated whether education on the iodized salt at household levels improves iodine status.

Objective: This study aimed to determine the effect of behaviour change communication on the use of iodised salt on median Urinary Iodine Concentration among children age 6-59 months.

Materials and Methods: A clustered Randomized Control Trial (CRCT) was carried out among children age 6-59 months and their index mothers, care givers in Arsi Zone, central highlands of Ethiopia from February 2017 to April 2019. "Kebeles" (small administration units) were taken as clusters and randomly assigned to either the intervention or control arm. There was a sufficient buffer zone between the intervention and control clusters to avoid information contamination. Mothers, Care givers and their index children were selected from both intervention and control clusters using simple systematic random sampling technique at baseline. Data on the background characteristics and Median Urinary Iodine Concentration (MUIC) were collected from mothers/ caregivers and their children age 6-59 months, respectively. Behaviour change communication was given on the intervention clusters for 15 months using explanatory poster and demonstration method. At the end line urine sample was taken from the same children and Median Urinary Iodine Concentration (MUIC) was analyzed with ammonium persulfate methods in Ethiopian Public Health Institute laboratory and iodine deficiency was stated at MUIC $<100 \mu \mathrm{g} / \mathrm{L}$. Descriptive statistics and a Generalized Estimating Equations (GEE) model was fitted to isolate independent predictors median Unirinary Iodine Concentration.

Results: At baseline, 812 and endpoint 715 mothers/ caregivers and their paired children were enrolled in the study. Iodine deference (ID) lowered to $6 \%$ and MUIC (25th-75th percentiles [p25-p75]) higher $(209.9 \mu \mathrm{g} / \mathrm{L}$ [143-400]) $\mu \mathrm{g} / \mathrm{L}$ at endpoint than the baseline 107.7 $\mu \mathrm{g} / \mathrm{L}(103,112)$. Generalized Estimating Equations analys Better to Gibe P Valuees showed that being in the intervention group increased MUIC mean difference by $11.48 \mu \mathrm{g} / \mathrm{L}(\beta=11.48, \mathrm{P}<0.05)$ and Height for age Z-score was also positively 
associated with MUIC mean difference $(\beta=1.79, \mathrm{P}<0.05)$. Like was there also a positive association between Median Urinary Iodine Concentration and sex $(\beta=5.004, P<0.05)$, food processing using iodized salt $(\beta=10.635, P<0.05)$ and adding iodine to food the end of cooking $(\beta=11.194, \mathrm{P}<0.05)$.

Conclusion: The study highlighted a positive effect of behaviour change communication on median Urinary Iodine Concentration implying the need for galvanizing efforts on the proper use of iodized salt and proper time of adding the salt into the food during cooking to improve iodine status of children and introduction complementary food at early age of the children facilitate the adequate intake of iodide.

\section{Introduction}

Iodine deficiency is the primary cause of preventable brain damage and growth retardation in children during the first few years of their [1]. Nearly thirty per cent of the world's population lives in areas with iodine deficiency [Iodine Global Network, www. ign.org]. Globally, universal salt iodization intervention program has been initiated to control iodine deficiency disorders [IDD] [2]. World Health organization (WHO) recommended that the deficiency of iodine corrected by increasing iodine intake through fortified table salt which required four major components of implementing strategies. Among these strategies are correction of iodine deficiency, surveillance including monitoring and evaluation, educate the public to qualify iodise salt utilization and intersectoral collaboration and advocacy and communication to mobilize public health authorities are frontline for the Control of IDD through the world [3]. Iodised salt intervention impact indicator principally median urinary iodine level is recommended in younger children population.

Most studies attempted to measure the prevalence of IDD based on goitre rate in school-age children at sever development stage of iodine deficiency. Additionally, these studies frequently focused to clinical signs of iodine deficiency after it becomes irreversible stage of disorder. In many parts of the world, children's diets contain insufficient micronutrients and deficiencies are widespread because of consuming a less or lack of diverse nutrient-dense foods [4]. Due to iodine deficiency, mental impairment and physical damage among children prevalent [5]. After more than two decades of implementing iodized salt as an intervention modality in Ethiopia, the problem of iodine deficiency is still prevalent. There was not an any longitudinal study that determined the effect of behaviour change communication promoting the proper use of iodised salt on prevention and control of IDD. This study started by quantifying iodine found in table salt at household level and assessed women's knowledge and attitude concerning prevention of IDD at the same time [6]. Currently, there is a tremendous change in implementation of universal iodised salt intervention in Ethiopia [6,7]. Given the fact that the government is making all efforts to avail iodized salt to the population, we hypothesised that the iodine deficiency disorder is related to the improper use of iodized salt at the household level. In this study we set out to determine the effect of behavioural modification of women through self-monitoring, behavioural contracts and goal setting for safely and adequately utilization of iodised salt in the households on iodine status of children 6-59 months.

\section{Materials and Methods}

\section{Study Area and Period}

The study was conducted from February 2018 to April 2019 (for 15 months) in Central highland of Ethiopia which includes area with altitude ranging from 2100 to 3000 found near to Arsi Bale plateau and the neighbouring of Chilalo Mountain. This includes, Tiyo, Limuna Bilalo, Digeluna Tijo ditricts and Asella Town that are found in a highland ecological zone. Historical annual rainfall ranges from $2200-2350 \mathrm{~mm}$ [8]. This study focused on the highland area as its surface layer exposed is likely to lose iodine through erosion and leaching [9]. Community based Cluster Randomized Control Trial (CRCT) design was used. Sixteen kebeles were selected from Highland Districts of Arsi Zone and randomly assigned either to intervention group or control group. All children age $6-59$ months and their pair mothers/caregivers found in districts Central Highland of Ethiopia were considered as the source population while children age 6 to 59 months old and their pair mothers/caregivers selected for this study form selected districts found in Central Highland of Ethiopia were considered as study population.

A total sample size of 829 mother child pair (415 intervention and 415 control were determined using Gpower 3.0 software with assuming a power of $95 \%$, precision of $5 \%$, effect size of 0.125 and ration of intervention to conrol of one. Multistage sampling method was applied to allocate intervention and control clusters randomly. First, sixteen kebeles were randomly assigned to either intervention or control cluster using Emergency Nutritional Assessment (ENA) software and eight Kebeles were allocated to intervention, while the remainder eight were allocated to control. Finally, individual households $(\mathrm{HH})$ and correspondent mothers/caregivers with their index children 6-59 months were selected using systematic random sampling technique. During the first months of survey, assessment of women's knowledge and attitude (KA) about prevention of IDD and iodised salt use and quantifying iodine found in table salt was done at household and wholesale market level [6]. A total of 812 children urine samples were collected and analyzed for MUIC at baseline [7]. The intervention included 452 and 363 children and their pair mothers/caregivers from clustered inter- 
vention and control groups, respectively. Mothers/ caregivers were oriented about the need of requisition urine specimen collection from their children before distributing specimen collection clean cups. To keep the need midurine specimen, for the procedure was demonstrated to mothers/ caregivers. Mid urine specimens were collected from a total of 715 children at the endline. After collection, each specimen was transferred to labelled clean tubes and packed in cold-boxes and transported to Ethiopian Public Health Institute. The laboratory professionals were given an orientation to prevent contamination and keeping the specimen tubes as tight closed to protect evaporation in laboratory. Other important cares were taken for specimen during transfer and storage in laboratory.

\section{Intervention Design: Self-Monitoring, Behavioral Con- tracts, and Goal Setting}

The communication activities among Health Extension Workers
(HEW) played an important role. The BCC was given for 15 months with every 2 weeks frequency for each kebels by correspondent trained HEW and supervised during intervention event conducted and feedback was given for each HEW after her/his completion of each intervention event. Women in the intervention clusters were provided with self-monitoring, behavioral contracts, and goal setting form February 2018 to April 2019 for sustainable and modifiable iodised salt utilization and. These activities were accomplished mainly by HEW through regular time (every two weeks) interval. Barriers that could obstruct use of iodised salt in the intervention programme such as price of the iodized salt, women's behaviour, adverse events, availability, taste and at times dietary beliefs were addressed. Most of the intervention time women were invited to raise about the massages that were needed revision or clarification any of knowledge or behavioural barriers at their homes related to iodide nutrient intake (Figure 1).

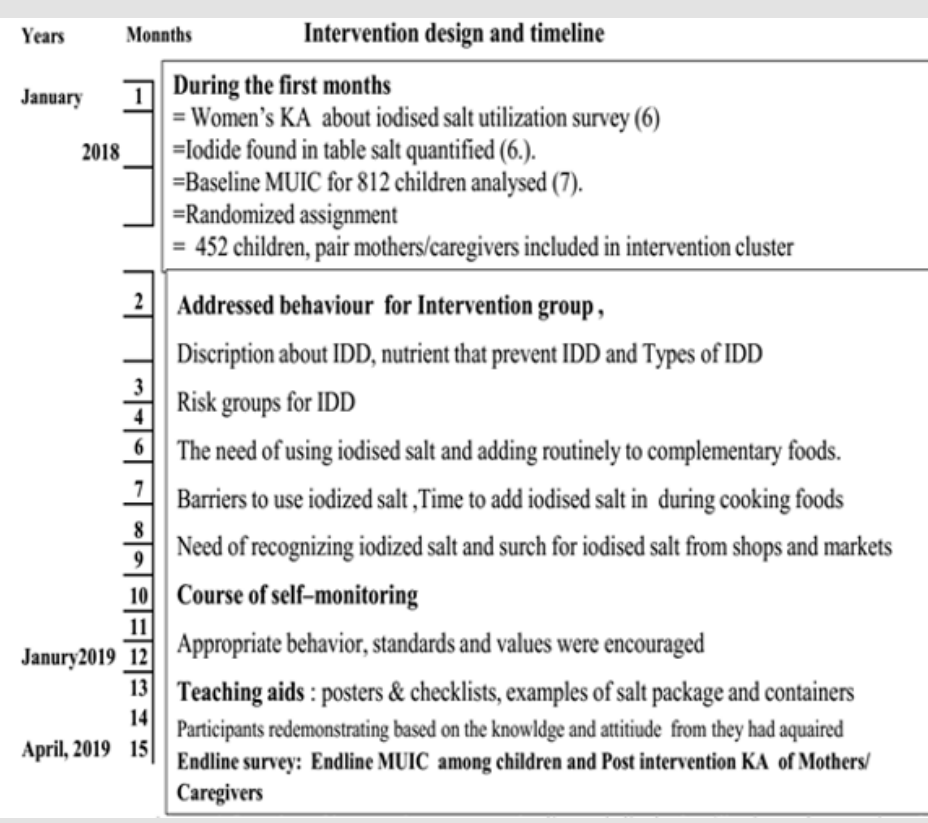

Figure 1: Overview of intervention program, timeline on iodised salt utilization and prevention of IDD in central Highland of Ethiopia, 2019

\section{Measurements}

\section{Laboratory Procedure for Iodine Determination from Mid Urine}

MUIC were analysed with ammonium persulfate methods in Ethiopian Public Health Institute laboratory.

The following steps used for analysing median urine iodine concentration.

1. In first, for each specimen, shaking was done to suspend sediment.

2. from each urine sample $250 \mu \mathrm{l}$ was pipetted into a $13 \mathrm{x}$ $100 \mathrm{~mm}$ test tube. Pipette was used for each iodine standard and then water was added as needed to make a final volume of $250 \mu \mathrm{l}$. Duplicate iodine standards and a set of internal urine standards were included in each assay.

3. One ml $1.0 \mathrm{M}$ ammonium persulfate was added to each test tube.

4. All test tubes were heated for 60 minutes at 100 OC.

5. Each test tube was cooled to room temperature.

6. Afterwards $2.5 \mathrm{ml}$ arsenious acid solution was added and mixed by inversion or vortex and then the test tube was allowed to stand for 15 minutes.

7. Subsequently, $300 \mu \mathrm{l}$ of ceric ammonium sulphate solution was added to each tube (quickly mixed) at 15-30 second intervals between successive tubes. A stopwatch was used for this 
practice at 15 seconds interval.

8. Each test tube contained treated specimen was allowed to sit at room temperature. 9. Exactly after 30 minutes, ceric ammonium sulphate was added to the first tube and its absorbance was read at $420 \mathrm{~nm}$.

9. Successive tubes were read at the same interval of adding the ceric ammonium sulphate.

\section{MUIC Laboratory Result Remarks}

Cut-off value for iodine adequacy was indicated with the reference of WOH, MUIC $100 \mu \mathrm{g} / \mathrm{L}$ and higher substantially adequate. However, MUIC blow $100 \mu \mathrm{g} / \mathrm{L}$ categorized as inadequate and this was also further categorized into insufficient (50 to $99 \mu \mathrm{g} / \mathrm{L}$ ) and severe $(<50 \mu \mathrm{g} / \mathrm{L})$ iodine deficiency [10].

\section{Anthropometric Measurements}

Children's height and weight $(\mathrm{Wt})$ were measured according to standard procedures recommended by WHO. Weight was measured using hanging spring balance for children age $<2$ years and digital scale for children 2 years and above without shoes and with light cloths. Besides, height was measured bare foot using a a stadiometer for children in age group 24 months and above. For children less than 24 months, recumbent length board was used for and each child rested in relaxed manner parallel to the long axis of the board and measurement was taken using two trained data collectors. Weight reading and height reading take to the nearest 0.1 $\mathrm{kg}$ and $0.1 \mathrm{~cm}$, respectively. Average reading of two independently observers were used for the final analyses $[11,12]$.

\section{Data Processing and Analysis}

At the first step, data entering children's height (Ht), weight
(Wt), age and sex were entered using Emergency Nutrition Assessment (ENA) software to determine children nutritional status. These variables were converted into HAZ and Wt for Ht (WHZ) for individual study subjects. HAZ > - Z Z-score standard deviation (ZSD) predicts as normal growth status and HFA $<-2$ ZSD evidenced that child's growth was stunted. In addition, weight for height $\mathrm{Z}$ score (WHZ) was also generated to determine wasting among [11,12]. Anthropometric and other data were entered into EpiData 3.0 software and transferred and analysed using the Statistical Package for Social Science statistical software for windows, version 21. Differences between baseline and endpoint MUIC were compute. The association between MUIC and different background characteristics of the study participants was done both for the control and intervention groups for the baseline and endline survey. The differences of difference between intervention and control groups and other variables significance against MUIC declared at T-test $\mathrm{pv}<05$. Variables that had P $>0.2$ were taken for further analyses with Generalized Estimating Equations. The results were presented using with Beta coefficients $(\beta)$ and $95 \%$ confidence intervals.

\section{Results}

At baseline 812 (98.9\%) were participated, but 715 (87.1\%) of study subjects pursued their intervention in the endlien survey. This study had specifically taken a close monitoring on 453 (100\%) study participants form intervention group and 262 (73\%) study participants from the control group throughout the intervention period. From 715 mothers/ caregivers, $70.21 \%$ were age between 20 -35years and $21.4 \%$ were illiterate. Regarding children, $48.67 \%$ were females. Children age $<24$ months were $49.8 \%$ at baseline was $28.39 \%$ at the end line survey, because of their age increased by 15 months, which was spent for this intervention (Table 1).

Table 1: Mothers' / caregivers' and paired children Socio- demographic status of in Central Highland of Ethiopia, 2018.

\begin{tabular}{|c|c|c|}
\hline Variables & $\begin{array}{c}\text { Frequency } \\
(n=715)\end{array}$ & Percent \\
\hline \multicolumn{3}{|l|}{ Maternal Age } \\
\hline Age $<20$ & 68 & 9.51 \\
\hline Age 2035 & 502 & 70.21 \\
\hline Age $>35$ & 145 & 20.28 \\
\hline \multicolumn{3}{|c|}{ Education Levels } \\
\hline Illiterate & 153 & 21.4 \\
\hline Grade 1-4 & 146 & 20.42 \\
\hline Grade 5-8 & 273 & 38.18 \\
\hline Grade 9-12 & 143 & 20 \\
\hline \multicolumn{3}{|c|}{ Marital Status } \\
\hline Single & 22 & 3.07 \\
\hline Married & 650 & 90.91 \\
\hline Divorced & 32 & 4.48 \\
\hline Widowed & 11 & 1.54 \\
\hline Occupation & & \\
\hline
\end{tabular}




\begin{tabular}{|c|c|c|}
\hline Housewife & 478 & 66.85 \\
\hline Farmer & 173 & 24.2 \\
\hline Businesswomen & 37 & 5.17 \\
\hline Gov/NGO employee & 7 & 0.98 \\
\hline Daily labourer & 20 & 2.8 \\
\hline \multicolumn{3}{|l|}{ Annul income (Birr) } \\
\hline$<1000$ & 235 & 32.87 \\
\hline $1000-5,000$ & 411 & 57.48 \\
\hline $5001-10,000$ & 56 & 7.83 \\
\hline$>10,000$ & 13 & 1.82 \\
\hline \multicolumn{3}{|l|}{ Age of Children } \\
\hline$>24$ months & 203 & 28.39 \\
\hline > 24 months & 512 & 71.61 \\
\hline \multicolumn{3}{|l|}{ Sex of Children } \\
\hline Female & 350 & 48.95 \\
\hline Male & 365 & 51.05 \\
\hline Total & 715 & $100 \%$ \\
\hline
\end{tabular}

At baseline survey, the prevalence of iodine deficiency (MUIC $<100 \mu \mathrm{g} / \mathrm{L}$ ) among children who participated in this study was higher (12.4\%) among intervention than control group (11.2\%). The prevalence among children who participated in this study at baseline was (11.8\% [7] and thus, the baseline finding was higher compared to endpoint survey (6.15\%), which was almost by half percent of ID decreased among study subjects. The prevalence of iodine deficiency among control group at endpoint survey did not change $(11.20 \%)$ from the baseline finding.

But, among intervention group during endline survey declined by more than $75 \%$ which was $3.0 \%$. Therefore, near to $94 \%$ of children participated in the study had met their need of iodide nutrient, but $5.3 \%$ of children had mild iodine deficiency that was MUIC 50 to $99 \mu \mathrm{g} / \mathrm{L}$. The prevalence of severe iodine deficiency considered as iodine intake below the estimated average requirement (EAR) of $65 \mu \mathrm{g} / \mathrm{L} /$ day (13) but at baseline was $0.12 \%$ (13) and at endline survey became $0.14 \%$. The MUIC during the endpoint assessment was very high $(209.9 \mu \mathrm{g} / \mathrm{L},[\mathrm{CI}=188.72,231.0])$ than the baseline MUIC $(107.7 \mu \mathrm{g} / \mathrm{L},[\mathrm{CI}=107.30,108.34])$ [7]. Also, p25-p75 MUIC increased $(143,400) \mu \mathrm{g} / \mathrm{L}$ at endpoint than that of baseline survey $(103,112) \mu \mathrm{g} / \mathrm{L}$. The MUIC was higher among control group (109.0) $\mu \mathrm{g} / \mathrm{L}$ than Intervention group (106.0) $\mu \mathrm{g} / \mathrm{L}$ at baseline survey but, at endpoint survey, intervention group increased more than two times (367.22) $\mu \mathrm{g} / \mathrm{L}$ of the control group (143.4) $\mu \mathrm{g} / \mathrm{L}$. The mean of endline -baseline difference of the difference in the quintiles of UIC between intervention and control groups showed that, the high proportion (44.1\% and $44.8 \%$ ) control group found at lower ranks (1st to $2 \mathrm{nd}$ ).

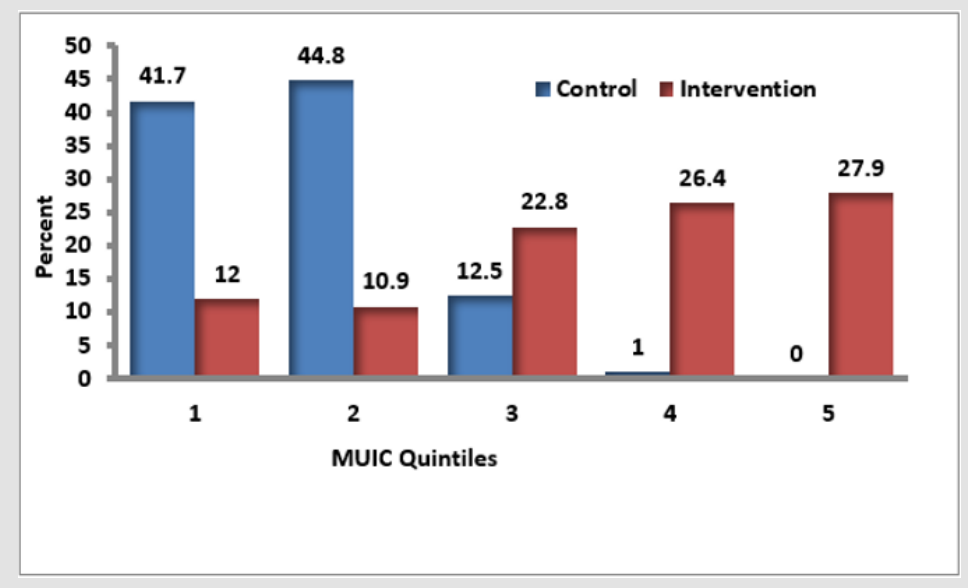

Figure 2: Mean endline-baseline difference of the differences in the quintiles UIC quintiles between intervention and control groups. 
Table 2: Mean MUIC differences between baseline and endpoint survey within different variables in Central Highland of Ethiopia, 2019.

\begin{tabular}{|c|c|c|c|c|c|}
\hline \multicolumn{6}{|c|}{ Median Urine Iodine Concentration } \\
\hline Variables & n (\%) & Mean (UIC $\mu \mathrm{g} / \mathrm{L}$ ) & $\begin{array}{c}\text { Mean Difference (UIC } \\
\mu \mathrm{g} / \mathrm{L} \text { ) }\end{array}$ & SE & $\mathbf{P}$ \\
\hline \multicolumn{6}{|l|}{ Groups } \\
\hline Intervention & $453(63.36)$ & 230.19 & 1 & & \\
\hline Control & $262(36.64)$ & 31.81 & 198.38 & 9.11 & $0.0001^{*}$ \\
\hline \multicolumn{6}{|l|}{ Age } \\
\hline$>24$ Months & $642(89.8)$ & 155.49 & 1 & & \\
\hline$<24$ Months & $73(10.2)$ & 166.37 & -10.88 & 18.6 & 0.567 \\
\hline \multicolumn{6}{|l|}{ Sex } \\
\hline Male & $367(51.33)$ & 157.74 & 1 & & \\
\hline Female & $348(48.67)$ & 157.24 & 0.5 & 11.3 & 0.955 \\
\hline \multicolumn{6}{|l|}{ HAZ } \\
\hline$>-2 S D$ & $530(74.0)$ & 184.78 & 1 & & \\
\hline$<-2 S D$ & $186(26.0)$ & 79.35 & 105.43 & 12.3 & $0.0001 *$ \\
\hline \multicolumn{6}{|l|}{ WHZ } \\
\hline$>-2 \mathrm{SD}$ & $584(81.7)$ & 149 & 1 & & \\
\hline$<-2 \mathrm{SD}$ & 131(18.3) & 192 & -43 & 14.4 & 0.005 \\
\hline \multicolumn{6}{|l|}{ WAZ } \\
\hline$>-2 \mathrm{SD}$ & $622(87.0)$ & 167.37 & 1 & & \\
\hline$<-2 S D$ & $93(13.0)$ & 91.5 & 75.87 & 16.6 & $0.0001 *$ \\
\hline
\end{tabular}

Diff: Difference; L: Litter; MD: Mean difference; $\mu$ g: microgram; $\mu \mathrm{g} / \mathrm{L}$ : Microgram per litter of urine; Z: Z score; SD: Standard Deviation; SE: Standard Error; Ht: Height; UIC: Urine Iodine concentration; P: significance

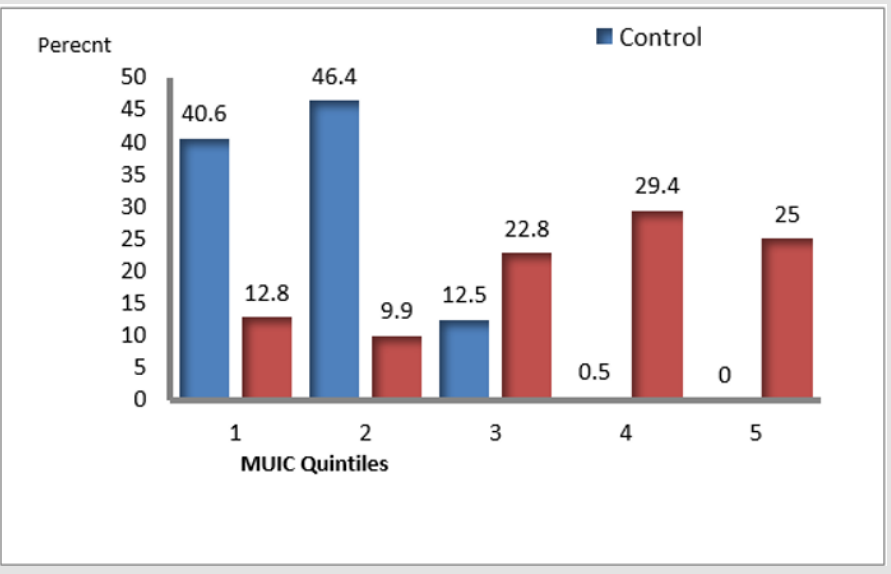

Figure 3: Endline differences in Mid urinary Iodin concentration between intervention and control.

\section{Discussion}

This study demonstrated improvement in the proportion of children who met the requirement in their requirement of iodine [6]. The proportion of children age 6-59 months who had adequate iodine nutrient (MUIC > $100 \mu \mathrm{g} / \mathrm{L}$ ) improved from $88.2 \%$ at baseline assessment [7] to $94 \%$ at the endline survey. In this study, end line survey showed that there was low proportion (6.1\%) of iodine deficient children compared to baseline survey [11.8\%] [7]. The entire prevalence $(6.1 \%)$ of iodine deficiency was very high compared to the study finding among Korean preschool children that reported a proportion of $3.9 \%$ [14]. The content of iodine found in table salt was quantified using titration method and this enabled the determination of the fact that households in this study area are consuming sufficiently iodized salt and met their requirement of 
iodine per person per day [6]. Consequently, in the baseline survey MUIC laboratory analysis reported that most children included in the survey had adequate iodine nutrient [7]. These the above inter-

Table 3: Mothers' / caregivers' knowledge and attitude status towards IDD prevention and iodised salt utilization in Central Highland of Ethiopia.

\begin{tabular}{|c|c|c|c|}
\hline Variables & Yes (\%) & No (\%) & pv \\
\hline \multicolumn{4}{|c|}{$\begin{array}{c}\text { Commune attitude in iodised salt } \\
\text { utilization }\end{array}$} \\
\hline Control & $178(67.68)$ & $85(32)$ & \\
\hline Intervention & $345(76.33)$ & $107(23.67)$ & 0.0001 \\
\hline \multicolumn{4}{|c|}{ Understand the cause of IDD } \\
\hline Control & $137(52.09)$ & $126(47.91)$ & \\
\hline Intervention & $369(81.64)$ & $83(18.36)$ & 0.347 \\
\hline \multicolumn{4}{|c|}{$\begin{array}{c}\text { Knowing about prevention method } \\
\text { of IDD }\end{array}$} \\
\hline Control & $83(31.56)$ & $180(68.44)$ & \\
\hline Intervention & $348(77.00)$ & $104(23.00)$ & 0.105 \\
\hline \multicolumn{4}{|c|}{$\begin{array}{l}\text { Behaviour to home food processing } \\
\text { with iodised salt }\end{array}$} \\
\hline Control & $109(41.45)$ & $154(58.55)$ & \\
\hline Intervention & 413(91.37) & $39(8.63)$ & 0.001 \\
\hline \multicolumn{4}{|c|}{$\begin{array}{l}\text { Use of salt container made from } \\
\text { rigid plastic/glass }\end{array}$} \\
\hline Control & $112(41.45)$ & $151(57.41)$ & \\
\hline Intervention & $432(95.58)$ & $20(4.42)$ & 0.13 \\
\hline \multicolumn{4}{|c|}{$\begin{array}{l}\text { Did you buy salt opened in the } \\
\text { market or in the house }\end{array}$} \\
\hline Control & $106(40.30)$ & $157(59.70)$ & \\
\hline Intervention & $428(94.69)$ & $24(5.31)$ & 0.131 \\
\hline
\end{tabular}

L: Litter; $\mu \mathrm{g} / \mathrm{L}:$ Microgram per litter of urine; $\mu \mathrm{g}$ : microgram; UIC: urine Iodine concentration; MD: Mean difference; P: significance

Table 4: Generalized Estimating Equations Predicting for response of MUIC mean difference odds to different predictors among children age 6 to 59 months, in central highland of Ethiopia.

\begin{tabular}{|c|c|c|c|}
\hline Variables & \multicolumn{2}{|c|}{ Parameter Estimates } \\
\hline & $\beta$ & $(95 \%$ CI) & 4.97 \\
\hline Intervention & 11.48 & $(3.60-13.74)^{*}$ & 1.51 \\
\hline Sex (Male) & 5.004 & $(1.92-13.58)^{*}$ & 0.68 \\
\hline Age (>24 months) & 0.664 & $(0.184-2.02)$ & 1.79 \\
\hline Height for Age >-2SD & 12,352 & $(1.04-14.65 *$ & 2.19 \\
\hline Weight for Height >-2SD & 0.703 & $(0.051-9.03)$ & 0.951 \\
\hline Attitude in Iodised salt utilization & 0.664 & $(0.85-2.39)$ & 0.79 \\
\hline Awareness of IDD & 0.728 & $(1.46-2.96)^{*}$ & 1.133 \\
\hline Food processing with iodised salt & 10.635 & $(1.005-6.23)^{*}$ & 2.36 \\
\hline
\end{tabular}

CI: Confidence interval; IDD: Iodine Deficiency Disorder; Mg: Milligram, L: litter; SD: Standard Deviation; MD: Mean Difference; P: significance 
This is expected to increase plasma thyroxin among study subjects. The MUIC was higher (209.9 $\mu \mathrm{g} / \mathrm{L})$, especially among intervention (367.22) group compared to the report of a study conducted among Norwegian toddlers (129 $\mu \mathrm{g} / \mathrm{L})$ [14]. But, Korean preschool children [15] had MUIC slightly less than study finding $(438.8 \mu \mathrm{g} / \mathrm{L})$. This could probably happen among population of developed countries and countries under transition that their diet is based on seafood and milk and milk products obtained from animal grazing grass and water containing reach iodine. Additionally, in these countries' history of IDD and iodine deficiency were reported under control since 2007 [16]. This could happen among population that have regular access to iodized salt. But, in developing countries like Ethiopia, the risk of IDD from iodine deficiency was not eliminated even if universal iodised salt intervention intensely implemented [2]. The current result implies that the need for galvanizing the behaviour change communication on iodised salt utilization at household level improve iodide status of children. The biochemical report of MUIC implies that BCC intervention on iodised salt utilization was effective in enabling people to meet their iodine requirement. This interventional study finding showed that there was very low (3\%) iodine deficiency among intervention group.

However, this finding had grate distinction with study finding among Norwegian children 18 months of age reported that no iodine differences $(<100 \mu \mathrm{g} / \mathrm{L})$ observed [14]. Through BCC, knowledge and attitude about prevention of IDD and utilization iodised salt among mothers/caregivers was improved and its effect on MUIC among children was changed. In this study, there was an improvement of attitude towards iodised salt utilization among intervention group (76.33\%) and no change (67.68\%) among control group at at the end line survey. Behavioural modification of home food processing with iodised salt among intervention group improved (91.37\%) and in the control group declined (41.45\%) at endline survey. WHO suggests that $<20 \%$ proportion of population with MUIC levels below $50 \mu \mathrm{g} / \mathrm{L}$ as a good progress towards sustainable IDD elimination [3].

In this study finding interestingly no study subjects who had MUIC below $50 \mu \mathrm{g} / \mathrm{L}$ and this predicts iodide among study group was at good level compared to WHO indicators [3]. This could be happened through BCC on increasing self-monitoring, behavioral contacts within the community to improve iodised salt use. This survey revealed that, despite a national salt iodisation programme, this community was unaware of the introduction and benefits of iodised salt. Most of the households used iodised salt with poor levels of knowledge in their food preparation. Like central highland of Ethiopia, many parts of the country have no other sources of iodine rather than iodised salt. So, the need for intensifying BCC adopting with the most important components of IDD control programme reassured the suitability of iodised salt intervention and projected to elimination of IDDD $[17,18]$. In Ethiopia, different strategies have been implemented in the past two decades to reduce the magnitude of IDD, but unsuccessful in monitoring and evaluating the iodised salt intervention and not included in Ethiopian demography and health survey $[19,20]$.

\section{Conclusion}

The findings indicated a significant effect of Behaviour change communication on the urinary Iodine level. At end line survey MUIC increased and prevalence also reduced to a minimum level especially to study subjects included in intervention group clustered area. This intervention project conducted three surveys in subsequent manner, first on knowledge and attitude about prevention of iodine deficiency disorders (IDD) among women and quantification of iodide found in table salt further strengthen our findings [6] and secondly to MUIC and associated factors Among Children Age 6 to 59 months [7] and finally, BCC in Iodised salt utilization and MUIC at end line survey. In future a longitudinal study to follow the occurrence of IDD among the same study group is recommended. We also recommend increasing BCC in parts of the country where most people have poor literary about iodised salt utilization and prevention of IDD. Finally, to Federal Democratic Republic of Ethiopian, Ministry of Health should initiate another option national and regional levels food and nutrition laboratories for better follow up of nutritional intervention especially to assess the content level of iodine in iodised salt and to satisfy different group of people through different direction with different barriers from the country side to the status of table salt iodising technology.

\section{Acknowledgement}

We would like to express their gratitude to Jimma University for financial support. They extend their special gratitude to Arsi Zone, health department, districts and kebeles administrative officers and all health Extension Workers for their assistance and cooperation at the time of data collection and accompanying field work and assisting the our one year and three month intervention program. Furthermore, we would also like to express their deep appreciation towards Ethiopian Public health institute food and nutrition laboratory officers for their technical work in their laboratory.

\section{Ethical approval}

Ethical approval was obtained from the Ethical Review Committee of the institutional Review Board (IRB) Institute of Health, Jimma University. A formal letter was written to the eight district Health offices and Health Extension Workers for permission and support until the intervention program completed. The study participants were clearly informed that their participation was voluntary, and they were free to participate in the study, or refuse at any time and for any reason without any penalty. Informed consent for their paired children and for them consent protocol was approved by the Ethical Review Committee. 


\section{Funding}

The research was fully funded by Jimma University.

\section{Competing Interests}

None declared.

\section{Author Contributions}

FA did the design of the intervention project, analysis and preparation of the whole manuscript, AM, participated in the analysis of data, write up and preparation and TB participated in the analysis of data, write up and final amendment of manuscript for publication. All authors read and approved the final manuscript.

\section{References}

1. (2007) WHO, FAO, ICCIDD, Iodine deficiency disorders and monitoring their elimination. A guide for program managers, third edition, World Health Organization.

2. Pieter Jooste, Maria Andersson, Vincent Assey (2018) Iodine Nutrition in Africa: The International Council for Control of Iodine Deficiency Disorders (ICCIDD) Global Network 2014.

3. (2008) World Health Organization. Iodine status worldwide WHO Global Database on Iodine Deficiency, Department of Nutrition for Health and Development World Health Organization, Geneva, USA.

4. (2013) UNICEF, UNICEF data Iodine deficiency.

5. Zimmermann MB (2012) The effects of iodine deficiency in pregnancy and infancy. Paediatric and Perinatal Epidemiology: Laboratory for Human Nutrition, Institute of Food, Nutrition and Health, Swiss Federal Institute of Technology.

6. Abebe Ferede, Muluemebet Abera, Tefera Belachew (2018) Knowledge and Attitude about Prevention of Iodine Deficiency Disorders (IDD) among Women and Quantification of Iodide found in Table Salt in Central Highland of Ethiopia. Biomed J Sci \& Tech Res 12(2): 9127-9135.

7. Abebe Ferede, Muluemebet Abera, Tefera Belachew (2019) Median Urinary Iodine Concentration and Associated Factors Among Children Age 6 to 59 Months in Central Highland of Ethiopia. Biomed J Sci \& Tech Res 17(4): 12938-12944.

8. Aklilu Mekasha, Lisanework Nigatu, Kindie Tesfaye, Alan J Duncanc (2013) Modeling the response of tropical highland herbaceous grassland species to climate change: The case of the Arsi Mountains of Ethiopia. Journal of Biological Conservation 168: 169-175.

9. Hetzel B (2000) Iodine-deficiency disorders. $10^{\text {th }}$ edn. Churchill Livingstone, London.

10. World Health Organization, WHO, UNICEF, ICCIDD Assessment of iodine deficiency disorders and monitoring their elimination: a guide for programme managers, 2001: $2^{\text {nd }} e d n$. Geneva, USA

11. (1995) World Health Organization Expert Committee on Physical Status. Physical status: the use and interpretation of anthropometry: report of a WHO Expert Committee, Geneva, USA.

12. (2007) World Health Organization child growth standards: head circumference-for-age, arm circumference-forage, triceps skinfold-forage and subscapular skinfold-for-age: methods and development.

13. (2001) IOM. Reference intakes for vitamin A, vitamin $\mathrm{k}$, arsenic, boron, chromium, copper, iodine, iron, manganese, molybdenum, nickel, silicon, vanadium and zinc: a report of the Panel on Micronutrients, Subcommittees on Upper Reference Levels of Nutrients and Interpretation and Uses of Dietary Reference Intakes, and the Standing Committee on the Scientific Evaluation of Dietary Reference Intakes. Institute of Medicine Washington DC, USA.

14. Aakre I, Markhus MW, Kjellevold M, Moe V, Smith L, et al. (2018) Sufficient iodine status among Norwegian toddlers 18 months in Norway. Journal of Food \& Nutrition Research 62: 1443.

15. Jeehhun Lee, Jeong Hyun Kim, Soo Youn Lee, Jun Hwa Lee (2013) Iodine status in Korean preschool children as determined by urinary iodine excretion. Eur J Nutr 53(2): 683-688.

16. (2019) World Health Organization. Iodine Deficiency in Europe: A continuing public health problem. Geneva, USA.

17. Dunn JT, Van der Haar F (1990) A practical guide to the correction of iodine defiiency. International Council for Control of Iodine Defiiency Disorders: Wageningen, The Netherlands.

18. Haxton DP (1996) From knowledge to policy to practice. In: Hetzel BS, Pandav CS, eds. SOS for a billion. The conquest of iodine defiiency disorders. New Delhi: Oxford University Press, pp. 147-164.

19. (2017) Central Statistical Agency Ethiopia. Ethiopia Demographic and Health Survey 2015.

20. (2015) Central Statistical Agency Ethiopia. Ethiopia Demographic and Health Survey 2010.

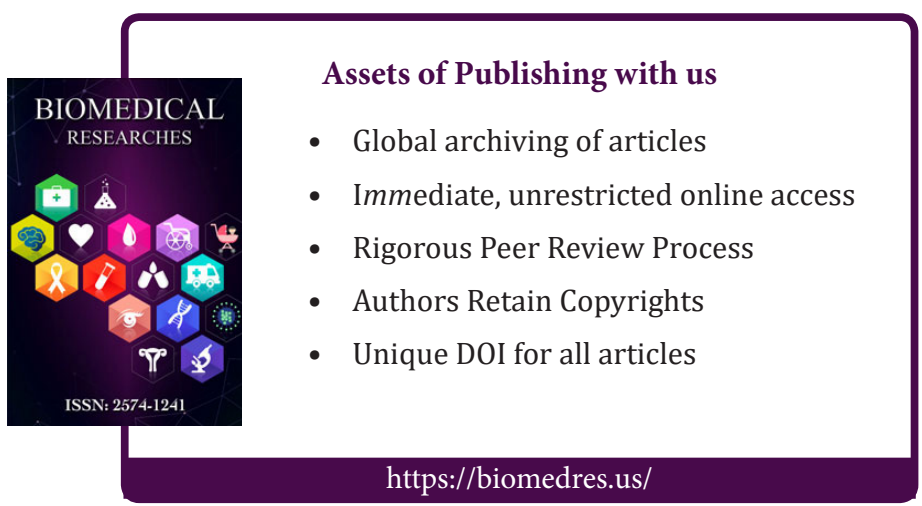

